\title{
Tinjauan Kebijakan dan Regulasi Pengembangan PLTS di Indonesia
}

\author{
Handoko Bayu, Jaka Windarta \\ Magister Energi, Sekolah Pascasarjana, Universitas Diponegoro;

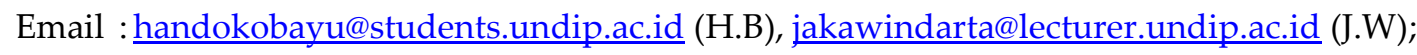

\begin{abstract}
Abstrak : Ketergantungan terhadap sumber energi fosil sebagai bahan bakar pembangkit listrik masih mendominasi sebagian besar sistem pemenuhan kebutuhan energi listrik di Indonesia. Usaha dalam rangka mengurangi fosil sebagai bahan bakar pembangkit dan beralih menggunakan energi baru terbarukan diupayakan oleh pemerintah dengan diterbitkannya aturan mengenai Kebijakan Energi Nasional. Komitmen pemerintah dalam rangka mendukung Kebijakan Energi Nasional, tercapainya 23\% penggunaan energi baru dan terbarukan pada tahun 2025 diwujudkan dengan berbagai macam kebijakan maupun regulasi, salah satunya pada pengembangan PLTS di Indonesia. Adanya kepastian dan payung hukum pelaksanaan pengembangan PLTS diharapkan mampu memberi kesempatan seluas luasnya untuk memaksimalkan potensi energi surya yang ada di Indonesia. Regulasi dari sisi teknis maupun fiskal harus terus diperbarui untuk mendukung investasi pada pengembangan PLTS.
\end{abstract}

Kata Kunci : Kebijakan Energi Nasional, Regulasi, PLTS

\section{Pendahuluan}

Indonesia adalah negara kepulauan yang terletak di garis khatulistiwa. Energi matahari yang luar biasa besar dan sepanjang tahun merupakan potensi sumber energi baru terbarukan yang sangat perlu untuk dikembangkan sekaligus mengurangi ketergantungan terhadap energi fosil sebagai sumber energi primer. Peran energi matahari sebagai salah satu sumber energi baru terbarukan masih bisa dimaksimalkan dalam meningkatkan rasio elektrifikasi. Sebagai energi yang ramah lingkungan, untuk mengurangi efek gas rumah kaca, sekaligus mendukung program nasional yang dicanangkan oleh pemerintah mengenai penyediaan energi dari sumber energi baru terbarukan salah satunya dari energi matahari.

\section{Potensi dan Arah Pengembangan}

Data yang disajikan oleh Dewan Energi Nasional (DEN) (Dewan Energi Nasional, 2020), Indonesia memiliki potensi energi surya yang cukup besar dan relatif stabil sepanjang tahun. Aplikasi dari energi surya ini ada dua macam, yaitu sebagai solar thermal untuk aplikasi pemanasan dan solar photovoltaic untuk pembangkitan tenaga listrik. Hampir seluruh wilayah Indonesia memiliki potensi pengembangan pembangkit listrik tenaga surya (PLTS) dengan daya rata-rata mencapai $4 \mathrm{kWh} / \mathrm{m}^{2}$. Berdasarkan wilayah, kawasan barat Indonesia memiliki potensi sekitar $4,5 \mathrm{kWh} / \mathrm{m}^{2} /$ hari dengan variasi bulanan mencapai $10 \%$. Sedangkan kawasan timur Indonesia memiliki potensi sekitar 5,1 
Vol. 2, No. 3, pp $123-132$

doi: $10.14710 /$ jebt.2021.10043

$\mathrm{kWh} / \mathrm{m}^{2} /$ hari dengan variasi bulanan sekitar $9 \%$. Adapun potensi tenaga surya secara nasional mencapai $4,8 \mathrm{kWh} / \mathrm{m}^{2} /$ hari atau setara dengan 207.898 MW. Peta potensi surya dapat dilihat pada Tabel 1.

Tabel 1.

Potensi Teknis Surya

\begin{tabular}{|c|c|c|c|c|c|}
\hline No. & Provinsi & Potensi (MW) & No. & Provinsi & Potensi (MW) \\
\hline 1 & Kalimantan Barat & 20.113 & 18 & Sumatera Barat & 5.898 \\
\hline 2 & Sumatra Selatan & 17.233 & 19 & Kalimantan Utara & 4.643 \\
\hline 3 & Kalimantan Timur & 13.479 & 20 & Sulawesi Tenggara & 3.917 \\
\hline 4 & Sumatera Utara & 11.851 & 21 & Bengkulu & 3.475 \\
\hline 5 & Jawa Timur & 10.335 & 22 & Maluku Utara & 3.036 \\
\hline 6 & Nusa Tenggara Barat & 9.931 & 23 & Bangka Belitung & 2.810 \\
\hline 7 & Jawa Barat & 9.099 & 24 & Banten & 2.461 \\
\hline 8 & Jambi & 8.847 & 25 & Lampung & 2.238 \\
\hline 9 & Jawa Tengah & 8.753 & 26 & Sulawesi Utara & 2.113 \\
\hline 10 & Kalimantan Tengah & 8.459 & 27 & Papua & 2.035 \\
\hline 11 & Aceh & 7.881 & 28 & Maluku & 2.020 \\
\hline 12 & Kepulauan Riau & 7.763 & 29 & Sulawesi Barat & 1.677 \\
\hline 13 & Sulawesi Selatan & 7.588 & 30 & Bali & 1.254 \\
\hline 14 & Nusa Tenggara Timur & 7.272 & 31 & Gorontalo & 1.218 \\
\hline 15 & Papua Barat & 6.307 & 32 & DI Yogyakarta & 996 \\
\hline 16 & Sulawesi Tengah & 6.187 & 33 & Riau & 753 \\
\hline \multirow[t]{2}{*}{17} & Kalimantan Selatan & 6.031 & 34 & DKI Jakarta & 225 \\
\hline & & & & Total & 207.898 \\
\hline
\end{tabular}

A. M. Fathoni, dkk (Fathoni et al., 2014) melakukan penelitian potensi PLTS di Indonesia dengan menggunakan simulasi software Retscreen, untuk PLTS yang terintegrasi dengan sistem interkoneksi jaringan. Simulasi dilakukan dengan memperhitungkan permintaan dan beban puncak setiap provinsi, memperoleh hasil tertinggi berada di Provinsi Sulawesi Selatan dengan potensi kapasitas pembangkit listrik tenaga surya sebesar $435 \mathrm{MW}$, sedangkan yang kapasitas pembangkit terendah di Provinsi Bali sebesar 0,29 MW.

Saat ini pemanfaatan EBT disektor ketenagalistrikan masih didominasi oleh penggunaan tenaga air, kemudian diikuti oleh pemanfataan panasbumi, biomassa, biodiesel, dan tenaga surya. Penggunaan PLTS masih terkendala dengan biaya investasi yang mahal terutama untuk komponen penyimpan energi dalam bentuk baterai maupun masalah pembebasan lahan untuk pengembangan PLTS dalam skala yang besar.

Dalam Rencana Umum Energi Nasional (RUEN) (Peraturan Presiden No. 22 Tahun 2017 Tentang Rencana Umum Energi Nasional, 2017), acuan indikasi rencana pengembangan surya per provinsi berdasarkan konsumsi listrik provinsi per kapita dan ketersediaan potensi surya per provinsi dapat dilihat pada Tabel 2. 
Tabel 2.

Indikasi Rencana Pengembangan Surya per Provinsi Tahun 2015 - 2025

\begin{tabular}{|c|c|c|c|c|c|c|c|c|c|c|c|c|}
\hline \multirow{2}{*}{ No. } & \multirow{2}{*}{ Provinsi } & \multicolumn{11}{|c|}{ Total Kapasitas Terpasang per Tahun (MW) } \\
\hline & & 2015 & 2016 & 2017 & 2018 & 2019 & 2020 & 2021 & 2022 & 2023 & 2024 & 2025 \\
\hline 1 & Nusa Tenggara Timur & 4,2 & 14,2 & 15,0 & 15,0 & 20,3 & 40,5 & 96,8 & 159,6 & 238,0 & 320,7 & 414,9 \\
\hline 2 & Kalimantan Barat & 1,3 & 1,3 & 1,6 & 15,1 & 24,3 & 43,8 & 88,3 & 140,9 & 209,2 & 282,4 & 366,4 \\
\hline 3 & Gorontalo & 0,7 & 4,7 & 9,7 & 9,7 & 19,7 & 19,7 & 35,7 & 65,4 & 128,8 & 218,6 & 343,3 \\
\hline 4 & Sumatera Selatan & 1,1 & 1,1 & 1,1 & 12,8 & 20,0 & 35,8 & 71,7 & 114,1 & 169,3 & 228,5 & 296,6 \\
\hline 5 & Nusa Tenggara Barat & 4,7 & 4,9 & 25,2 & 90,2 & 90,2 & 90,2 & 90,2 & 112,3 & 167,2 & 225,4 & 292,0 \\
\hline 6 & Sulawesi Barat & 0,5 & 0,5 & 0,5 & 2,4 & 9,8 & 23,3 & 60,5 & 100,7 & 150,4 & 202,6 & 261,8 \\
\hline 7 & Jambi & 1,0 & 1,0 & 3,0 & 7,1 & 13,6 & 27,1 & 60,7 & 98,6 & 146,7 & 197,9 & 256,3 \\
\hline 8 & Kalimantan Timur & 1,6 & 1,9 & 2,0 & 8,4 & 15,3 & 27,7 & 56,1 & 89,3 & 132,5 & 178,9 & 232,1 \\
\hline 9 & Sumatera Utara & 16,0 & 17,7 & 57,7 & 57,7 & 57,7 & 57,7 & 57,7 & 86,2 & 128,0 & 176,2 & 224,1 \\
\hline 10 & Sulawesi Tengah & 1,4 & 1,4 & 11,4 & 11,4 & 31,4 & 31,4 & 52,7 & 86,2 & 128,4 & 173,1 & 224,1 \\
\hline 11 & Kalimantan Tengah & 0,8 & 1,1 & 1,1 & 6,7 & 13,4 & 23,7 & 52,5 & 85,0 & 126,5 & 170,6 & 221,1 \\
\hline 12 & Papua & 7,8 & 8,2 & 19,4 & 19,4 & 39,4 & 39,4 & 50,7 & 84,2 & 125,7 & 169,3 & 218,8 \\
\hline 13 & Sulawesi Tenggara & 1,9 & 2,4 & 9,6 & 9,6 & 10,5 & 21,6 & 49,7 & 81,9 & 122,1 & 164,6 & 212,9 \\
\hline 14 & Aceh & 0,8 & 0,8 & 2,8 & 6,2 & 12,7 & 22,5 & 50,2 & 81,3 & 121,0 & 163,2 & 211,4 \\
\hline 15 & Maluku Utara & 4,5 & 4,6 & 9,6 & 9,6 & 9,7 & 18,9 & 47,3 & 78,3 & 116,8 & 157,3 & 203,5 \\
\hline 16 & Jawa Tengah & 0,4 & 0,4 & 0,4 & 6,7 & 12,3 & 22,1 & 44,6 & 71,7 & 106,6 & 143,8 & 186,4 \\
\hline 17 & Jawa Timur & 0,5 & 0,6 & 3,4 & 7,7 & 13,2 & 23,1 & 44,9 & 71,7 & 106,4 & 143,6 & 186,4 \\
\hline 18 & Sulawesi Selatan & 3,9 & 7,0 & 8,1 & 8,1 & 11,5 & 21,2 & 43,8 & 70,8 & 105,2 & 142,0 & 184,0 \\
\hline 19 & Maluku & 5,0 & 5,3 & 10,3 & 15,3 & 15,3 & 17,6 & 41,9 & 69,6 & 103,8 & 139,9 & 180,8 \\
\hline 20 & Papua Barat & 1,8 & 4,1 & 4,1 & 5,0 & 15,0 & 19,0 & 39,8 & 64,6 & 96,1 & 129,5 & 167,8 \\
\hline 21 & Jawa Barat & 0,3 & 0,3 & 0,4 & 6,8 & 11,5 & 20,2 & 39,3 & 62,7 & 93,1 & 125,6 & 163,0 \\
\hline 22 & Kalimantan Selatan & 1,9 & 3,9 & 3,9 & 4,8 & 9,7 & 18,1 & 38,0 & 61,5 & 91,5 & 123,5 & 160,0 \\
\hline 23 & Bengkulu & 0,6 & 0,7 & 0,7 & 3,1 & 8,2 & 16,5 & 37,3 & 61,2 & 91,3 & 123,0 & 159,2 \\
\hline 24 & Sumatera Barat & 1,7 & 2,0 & 2,9 & 4,6 & 9,3 & 17,2 & 35,9 & 58,1 & 86,4 & 116,6 & 151,0 \\
\hline 25 & Lampung & 1,3 & 1,6 & 1,6 & 2,1 & 6,5 & 13,5 & 31,3 & 51,6 & 77,0 & 103,8 & 134,3 \\
\hline 26 & Kepulauan Riau & 1,1 & 1,1 & 1,1 & 5,8 & 9,5 & 16,5 & 31,5 & 50,2 & 74,4 & 100,5 & 130,4 \\
\hline 27 & Sulawesi Utara & 3,8 & 3,8 & 3,8 & 3,8 & 5,6 & 11,5 & 26,5 & 43,7 & 65,1 & 87,8 & 113,6 \\
\hline 28 & Bangka Belitung & 1,6 & 1,6 & 3,6 & 3,6 & 5,9 & 11,7 & 25,9 & 42,4 & 63,2 & 85,2 & 110,3 \\
\hline 29 & Bali & 4,4 & 7,5 & 8,2 & 8,2 & 8,2 & 108,2 & 108,2 & 108,2 & 108,2 & 108,2 & 108,2 \\
\hline 30 & Kalimantan Utara & 0,4 & 0,6 & 0,6 & 3,6 & 6,6 & 12,0 & 24,3 & 39,1 & 58,1 & 78,5 & 101,7 \\
\hline 31 & Banten & 0,2 & 0,2 & 0,3 & 2,1 & 5,1 & 10,0 & 22,2 & 36,3 & 54,0 & 72,9 & 94,3 \\
\hline 32 & Riau & 0,9 & 1,0 & 1,0 & 1,0 & 4,1 & 9,0 & 21,8 & 36,2 & 54,1 & 72,8 & 94,2 \\
\hline 33 & D.I. Yogyakarta & 0,1 & 0,1 & 0,1 & 1,1 & 3,7 & 8,0 & 18,9 & 31,3 & 46,8 & 63,0 & 81,5 \\
\hline 34 & Jakarta & 0,2 & 0,2 & 0,3 & 0,3 & 0,7 & 1,4 & 3,2 & 5,3 & 7,9 & 10,7 & 13,8 \\
\hline & Total Kapasitas Terpasang & 78,4 & 107,8 & 224,5 & 375,0 & 549,9 & 900,1 & $1.600,1$ & $2.500,2$ & $3.699,8$ & $5.000,2$ & $6.500,2$ \\
\hline & Total Tambahan/Tahun & & 29,4 & 116,7 & 150,5 & 174,9 & 350,2 & 700,0 & 900,1 & $1.199,6$ & $1.300,4$ & $1.500,0$ \\
\hline
\end{tabular}


Vol. 2, No. 3, pp $123-132$

doi: $10.14710 /$ jebt.2021.10043

PT. PLN (Presero) sebagai satu-satunya perusahaan negara yang diberi mandat untuk mengelola ketenagalistrikan, serta tanggung jawab dan tujuan PT. PLN (Persero) dalam hal pelayanan kelistrikan yang diperuntukan bagi masyarakat dalam rangka meningkatkan kesejahteraan dan kemakmuran rakyat secara adil dan merata (Tenriabeng et al., 2013). Penyediaan tenaga listrik dari hulu sampai dengan hilir menjadi tanggung jawab PT. PLN termasuk dalam hal pengembangan pembangkit listrik dari sumber energi primer jenis fosil dan EBT. Dalam (Keputusan Menteri Energi Dan Sumber Daya Mineral Republik Indonesia Nomor 1567K/21/MEM/2018 Tentang Pengesahan Rencana Usaha Penyediaan Tenaga Listrik PT PLN (Persero) Tahun 2018 s.d. 2027, 2018), rencana pengembangan pembangkit berbasis EBT terlihat pada tabel 3.

Tabel 3.

Rencana Pengembangan EBT

\begin{tabular}{clcccccccccccc}
\hline No. & Pembangkit EBT & Kap. & 2019 & 2020 & 2021 & 2022 & 2023 & 2024 & 2025 & 2026 & 2027 & 2028 & Total \\
\hline 1 & Panas Bumi & MW & 190 & 151 & 147 & 455 & 245 & 415 & 2.759 & 45 & 145 & 55 & 4.607 \\
2 & PLTA & MW & 154 & 326 & 755 & - & 182 & 1.484 & 3.047 & 129 & 466 & 1.467 & 8.010 \\
3 & PLTM & MW & 140 & 39 & 479 & 200 & 168 & 232 & 27 & 20 & 20 & 10 & 1.335 \\
4 & PLTS & MWp & 63 & 78 & 219 & 129 & 160 & 4 & 250 & - & 2 & 2 & 907 \\
5 & Angin & MW & - & - & 30 & 360 & 260 & 50 & 150 & - & - & 5 & 855 \\
6 & PLT Biomass/Sampah & MW & 12 & 139 & 60 & 357 & 50 & 103 & 19 & 5 & 15 & 35 & 795 \\
7 & Laut & MW & - & - & 7 & - & - & - & - & - & - & - & 7 \\
8 & Biofuel & Ribu KL & 520 & 487 & 290 & 167 & 151 & 146 & 154 & 159 & 166 & 175 & 2.415 \\
\hline & Total & MW & 560 & 933 & 1.697 & 1.501 & 1.065 & 2.287 & 6.251 & 199 & 648 & 1.574 & 16.715 \\
\hline
\end{tabular}

Sumber : Keputusan Menteri ESDM No. 39K/20/MEM/2019 tentang Rencana Umum Penyediaan Tenaga Listrik PT. PLN (Persero) 2019-2028

Dari sisi lingkungan, pembangkit listrik merupakan salah satu produsen energi yang menghasilkan emisi gas rumah kaca yang cukup besar karena penggunaan bahan bakar fosil. Penggunaan energi terbarukan seperti surya, tenaga air dan panas bumi diasumsikan tidak menghasilkan emisi gas rumah kaca. Pada dasarnya setiap pembangkit listrik akan menghasilkan emisi gas $\mathrm{CO}_{2}$ atau sering disebut sebagai jejak karbon (carbon footprint) baik selama pembangunannya maupun saat operasi (Artiningrum, 2014). Jejak karbon didefinisikan sebagai jumlah total gas $\mathrm{CO}_{2}$ dan gas rumah kaca lainnya, yang dikeluarkan sepanjang siklus hidup penuh suatu proses atau produk.

Untuk pembangkit listrik, jejak karbon tersebut dihitung dalam gram ekivalen gas $\mathrm{CO}_{2}$ per $\mathrm{kWh}$ listrik yang dihasilkan ( $\mathrm{gCO}_{2} \mathrm{eq} / \mathrm{kWh}$ ). Dalam operasinya membangkitkan listrik, secara praktis pembangkit listrik tenaga surya tidak menghasilkan emisi yang berarti jika dibandingkan dengan pembangkit listrik dengan bahan bakar batubara. Disamping karbon dioksida, pembangkit listrik tenaga surya menghasilkan sulfur dioksida, nitrogen oksida, polutan atmosfir yang lebih sedikit jika dibandingkan dengan pembangkit listrik dengan menggunakan batubara ataupun gas. Data jejak karbon untuk berbagai tipe pembangkit listrik dapat dilihat pada tabel 4 . 
Tabel 4.

Data jejak karbon

\begin{tabular}{clc}
\hline No. & Jenis Pembangkit Listrik & Jejak Karbon $\left(\mathrm{gCO}_{2} \mathrm{eq} / \mathrm{kWh}\right)$ \\
\hline 1 & PLTU Batubara & $>1.000$ \\
2 & PLTG BBM & 650 \\
3 & PLTG Gas & 500 \\
4 & PLTU Biomassa & $25-93$ \\
5 & Photovoltaik & 58 \\
6 & Energi laut & $25-50$ \\
7 & PLTA dengan waduk & $10-30$ \\
8 & PLTA tanpa waduk & $<5$ \\
9 & PLTN & 5 \\
10 & PLTB & $4,64-5,25$ \\
\hline
\end{tabular}

Penelitian yang dilakukan oleh Peishi Wu, dkk (Wu et al., 2017) menguji keuntungan emisi gas rumah kaca (GRK) dari instalasi fotovoltaik dengan melakukan penilaian siklus hidup (Life Cycle Assesment) untuk pembangkit listrik tenaga batu bara dan pembangkit listrik berbasis PV. Laju emisi GRK untuk kedua sistem masing-masing adalah 975,2 gCO 2 eq/kWh dan 36,75 gCO2eq/kWh. Selisih nilai emisi yang dihasilkan, menunjukkan kelebihan dari pembangkit listrik tenaga surya (fotovoltaik) sehingga ramah lingkungan.

\section{Kebijakan dan Regulasi}

Tanggung jawab pemerintah dalam rangka pengelolaan energi nasional, memiliki peran yang sangat menentukan untuk keberlangsungan penyediaan energi nasional yang aman, andal serta ramah lingkungan. Untuk melaksanakan ketentuan Pasal 11 ayat (2) (Undang - Undang Republik Indonesia No. 30 Tahun 2007 Tentang Energi, 2007), pemerintah menyusun Kebijakan Energi Nasional termasuk didalamnya mengenai pembangkit tenaga listrik yang berbahan bakar EBT. Dalam rumusan Kebijakan Energi Nasional (KEN), target pada tahun 2025 peran Energi Baru dan Energi Terbarukan paling sedikit 23\% (dua puluh tiga persen) dan pada tahun 2050 paling sedikit $31 \%$ (tiga puluh satu persen) sepanjang keekonomiannya terpenuhi (Peraturan Pemerintah Republik Indonesia Nomor 79 Tahun 2014 Tentang Kebijakan Energi Nasional, 2014). Untuk memenuhi bauran energi sebagaimana dimaksud dalam KEN dilakukan upaya upaya antara lain, memaksimalkan penggunaan energi bersih/terbarukan, meminimalkan peran minyak bumi, mengoptimalkan pemanfaatan gas bumi dan energi baru, menggunakan batubara sebagai andalan pasokan energi nasional dan memanfaatkan nuklir sebagai pilihan terakhir. Porsi dari EBT sesuai amanat KEN menunjukkan tren yang meningkat, namun pada poin lain, peran batubara juga masih menjadi andalan sebagai sumber energi primer. Dalam rangka peningkatan kapasitas infrastruktur PLT EBT termasuk energi surya, pemerintah mengeluarkan beberapa peraturan untuk mengatur pengembangan pembangkit listrik yang dibedakan menjadi 2 arah kebijakan mengenai pembangkit yang bersifat komersial dan non komersial. Penentuan jenis EBT yang akan digunakan sebagai sumber energi primer ditentukan berdasarkan pada potensi masing - masing wilayah yang bisa dioptimalkan. Pengaturan mengenai harga jual beli tenaga listrik diatur sedemikian rupa dengan memperhatikan nilai keekonomian pada sistem pembangkitan. 
PLTS yang bersifat komersial berupa PLTS komunal pada daerah tertentu untuk mencukupi kebutuhan sendiri off grid maupun on grid. Sesuai (Peraturan Menteri Energi Dan Sumber Daya Mineral Republik Indonesia No. 50 Tahun 2017 Tentang Pemanfaatan Sumber Energi Terbarukan Untuk Penyediaan Tenaga Listrik, 2017), skema pembelian tenaga listrik dari PLTS oleh PT. PLN diatur dengan memperhatikan, sistem ketenagalistrikan setempat dapat menerima pasokan tenaga listrik yang menggunakan sumber energi sinar matahari, dimaksudkan untuk menurunkan Biaya Pokok Penyediaan (BPP) Pembangkitan di sistem ketenagalistrikan setempat dan/atau memenuhi kebutuhan tenaga listrik di lokasi yang tidak ada sumber energi primer lain. Dalam hal BPP Pembangkitan di sistem ketenagalistrikan setempat di atas rata-rata BPP Pembangkitan nasional, harga pembelian tenaga listrik dari PLTS paling tinggi sebesar 85\% (delapan puluh lima persen) dari BPP Pembangkitan di sistem ketenagalistrikan setempat, dengan skema kerjasama membangun, memiliki, mengopersikan dan mengalihkan (Build, Own, Operate, and Transfer/BOOT). Peningkatan elektrifikasi untuk daerah terpencil juga diatur oleh Pemerintah melalui (Peraturan Menteri Energi Dan Sumber Daya Mineral Republik Indonesia No. 38 Tahun 2016 Tentang Percepatan Elektrifikasi Di Perdesaan Belum Berkembang, Terpencil, Perbatasan, Dan Pulau Kecil Berpenduduk Melalui Pelaksanaan Usaha Penyediaan Tenaga Listrik, 2016) memberi kesempatan kepada daerah melalui badan usaha untuk melaksanakan kegiatan usaha penyediaan tenaga listrik dalam skala kecil untuk meningkatkan rasio elektrifikasi setempat yang belum terjangkau oleh jaringan listrik. Pasal 18 ayat 2 b menekankan bahwa rasio elektrifikasi pada wilayah usaha dalam usaha penyediaan tenaga listrik untuk skala kecil yang telah dimiliki badan usaha tersebut telah mencapai paling sedikit $95 \%$ (sembilan puluh lima persen).

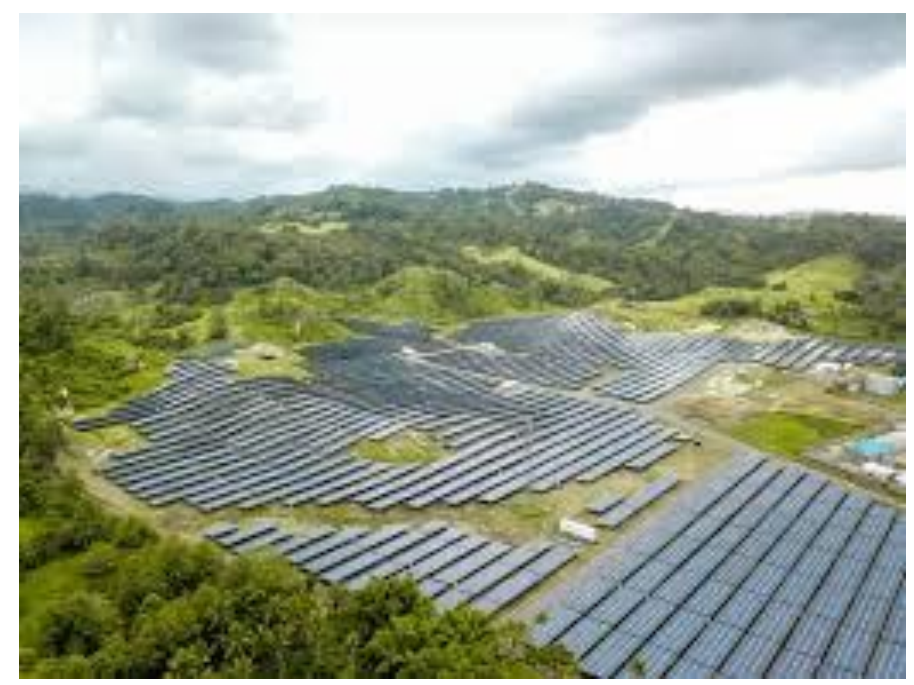

Gambar 1. Kondisi PLTS Likupang (Sumber : setkab.go.id)

PLTS komunal terbesar di Indonesia saat ini, terletak di Desa Wineru, Kecamatan Likupang Timur, Kabupaten Minahasa Utara, Provinsi Sulawesi Utara (Kementerian Energi dan Sumber Daya Mineral Republik Indonesia, 2020). PLTS Likupang dibangun sejak Power Purchase Agreement (PPA) tahun 2017 akhir dan memakan waktu sekitar 1,5 tahun dengan total biaya investasi mencapai USD 29,2 juta. Sebanyak 64.620 hamparan panel surya tersusun rapi membentang di atas ladang seluas 29 hektar. Kehadiran alat penangkap sinar matahari tadi difungsikan oleh Vena Energy sebagai sumber 
energi listrik baru sejak 5 September 2019. Rata-rata setiap harinya Pembangkit Listrik Tenaga Surya (PLTS) Likupang menyalurkan listrik mencapai 15 MW meskipun memiliki kapasitas terpasang 21 Mega Watt Peak (MWp). Sistem produksi listrik PLTS Likupang langsung terhubungan secara online dengan jaringan listrik milik PLN dengan kontrak jual beli listrik berlangsung selama 20 tahun dengan skema Built, Own, Operate, Transfer (BOOT).

Dari sisi PLTS non komersial pemerintah berupaya meningkatkan pengembangan pembangkit melalui sistem PLTS atap. Melalui deklarasi gerakan nasional sejuta surya atap yang ditandatangani pada tanggal 13 September 2017 oleh perwakilan Direktorat Jenderal Energi Baru Terbarukan dan Konservasi Energi Kementerian Energi dan Sumber Daya Mineral (EBTKE KESDM), Kementerian Perindustrian, Badan Pengkajian dan Penerapan Teknologi (B2TKE BPPT), Masyarakat Energi Terbarukan Indonesia (METI), Konsorsium Kemandirian Industri Fotovoltaik Indonesia, Asosiasi Energi Surya Indonesia (AESI), Asosiasi Pabrikan Modul Surya Indonesia (APAMSI), dan Perkumpulan Pengguna Listrik Surya Atap (PPLSA). Tujuan deklarasi gerakan nasional sejuta surya atap antara lain untuk mendorong dan mempercepat pembangunan PLTS atap di perumahan, fasilitas umum, perkantoran pemerintah, bangunan komersial dan kompleks indusrti hingga mencapai orde gigawat sebelum 2020, mendorong tumbuhnya industri nasional sistem fotovoltaik yang berdaya saing dan menciptakan kesempatan kerja, mendorong penyediaan listrik yang handal, berkelanjutan dan kompetitif, mendorong dan memobilisasi partisipasi masyarakat untuk mengurangi emisi gas rumah kaca dan ancaman perubahan iklim dan ikut mendukung terlaksananya komitmen Indonesia atas Paris Agreement (Undang - Undang Republik Indonesia No. 16 Tahun 2016 Tentang Pengesahan Paris Agreement To The United Nations Framework Convention on Climate Change (Persetujuan Paris Atas Konvensi Kerangka Kerja Perserikatan Bangsa-Bangsa Mengenai Perubahan Iklim), 2016) dan upaya mencapai tujuan Sustainable Development Goals (SDGs) (Vernon, 2015).

PLTS atap adalah proses pembangkitan tenaga listrik yang menggunakan modul fotovoltaik, yang diletakkan di atap, dinding, atau bagian lain dari bangunan milik pelanggan PLN. Manfaat pemasangan PLTS atap antara lain adalah menghemat tagihan listrik pelanggan PLN, aplikasi energi baru terbarukan menggantikan energi fosil, membantu mengurangi dampak perubahan iklim karena lebih ramah lingkungan (Kementerian Energi dan Sumber Daya Mineral, 2020). Sesuai dengan pasal 5 ayat 1 (Peraturan Menteri Energi Dan Sumber Daya Mineral Republik Indonesia No. 49 Tahun 2018 Tentang Penggunaan Sistem Pembangkit LIstrik Tenaga Surya Atap Oleh Konsumen PT. PLN (Persero), 2018), disebutkan bahwa "Kapasitas sistem PLTS atap dibatasi paling tinggi 100\% (seratus persen) dari daya tersambung pelanggan PT. PLN (Persero)". Manfaat utama dari pemasangan PLTS atap oleh pelanggan PLN adalah penghematan listrik, karena listrik yang menggunakan sistem PLTS atap akan mengurangi besarnya kWh listrik langganan dari PLN tiap bulannya. Sedangkan skema ekspor kelebihan kWh listrik dari PLTS atap pelanggan ke jaringan PLN tidak ditujukan untuk jual beli listrik secara komersial, melainkan menjadi cadangan penghematan listrik yang hanya dapat diakumulasikan selama 3 bulan. Cadangan listrik tersebut dalam perhitungan tagihan listrik PLN hanya bernilai $65 \%$ dari tarif dasar listrik (TDL) PLN dengan skema sebagai berikut.

Tagihan Listrik Pelanggan $(\mathrm{kWh})=$ Jumlah kWh Impor $-(65 \% \times$ Jumlah kWh Ekspor $)$

Dari simulasi pola penggunakan PLTS Atap pada Tabel 5, dapat diketahui bahwa pada bulan Desember 2018, pelanggan memasang PLTS atap (rata-rata konsumsi listrik dari PLN sebelum memasang PLTS atap sebesar $400 \mathrm{kWh} /$ bulan). Pada bulan Januari 2019, PLTS mulai memproduksi 
listrik sebesar $64 \mathrm{kWh}$ untuk dikonsumsi sendiri kWh sehingga pemakaian dari PLN menjadi 336 kWh. Selain konsumsi sendiri, PLTS juga mengekspor listrik ke PLN sebesar $21 \mathrm{kWh}$ (yang dikonversi menjadi $13 \mathrm{kWh}$, sesuai ketentuan nilai 65\% listrik ekspor) dan tagihan bulanan pelanggan pada Januari 2019 menjadi 323 kWh. Pada bulan Februari 2019, pelanggan menggunakan listrik dari PLN sebesar $20 \mathrm{kWh}$ untuk penerangan malam hari. Total produksi PV (siang) sebesar $85 \mathrm{kWh}$ diekspor ke PLN dan dikonversi menjadi $55 \mathrm{kWh}$ (sesuai ketentuan nilai 65\% listrik ekspor). Tagihan bulanan pelanggan pada Februari 2019 menjadi $-35 \mathrm{kWh}$ yang menjadi tabungan kWh sebagai pengurang tagihan bulan berikutnya. Pada bulan Maret 2019, konsumsi impor $20 \mathrm{kWh}$ dan $\mathrm{kWh}$ ekspor 55 kWh sehingga tagihan menjadi -70 kWh. Pada bulan April 2019. Akumulasi tabungan kWh bulan sebelumnya $(-70 \mathrm{kWh})$ dihabiskan. Tagihan akan dihitung menjadi $-35 \mathrm{kWh}$. Pada bulan Mei 2019, Rumah kembali dihuni sehingga kWh impor naik $336 \mathrm{kWh}$ dan $13 \mathrm{kWh}$ diekspor ke PLN Tagihan menjadi $288 \mathrm{kWh}$.

Tabel 5.

Simulasi Pola Produksi dan Konsumsi Listrik PLTS Atap (EBTKE - ESDM)

\begin{tabular}{lcccccc}
\hline \multicolumn{1}{c}{ Transaksi } & Des-19 & Jan-19 & Feb-19 & Mar-19 & Apr-19 & Mei-19 \\
\hline Akumulasi kWh Bulan Sebelumnya (a)=-(e) & 0 & 0 & 0 & 35 & 0 & 35 \\
kWh Impor (b) & 400 & 336 & 20 & 20 & 20 & 336 \\
kWh Ekspor (c) & 0 & 13 & 55 & 55 & 55 & 13 \\
Tagihan Bulanan (d)=(b)-(c)-(a) & 400 & 323 & -35 & -70 & -35 & 0 \\
Akumulasi kWh ke Bulan Depan (e) & 0 & 0 & -35 & -70 & -35 & 0 \\
\hline
\end{tabular}

Jika pelanggan menggunakan langsung listrik yang dihasilkan dari PLTS atap, tidak dikirim ke jaringan Listrik PLN, maka satu kWh listrik yang digunakan akan mengurangi $1 \mathrm{kWh}$ listrik yang dibeli dari PLN ( dinilai 100\%). Skema ini disebut sebagai net billing, dengan artian bahwa tidak terdapat transaksi tunai dalam perhitungan ekspor-impor listrik pelanggan PLTS atap.

Badan Usaha Pembangunan dan Pemasangan PLTS atap mempunyai tanggung jawab utama yaitu memastikan instalasi PLTS atap yang terpasang mememuhi memenuhi ketentuan administratif perijinan (ijin operasi) dan kaidah K2 (keselamatan dan kesehatan), baik dalam proses pemasangan PLTS atap maupun terkait interkoneksi PLTS atap ke jaringan PLN. Setiap instalasi tenaga listrik yang beroperasi wajib memiliki Sertifikat Laik Operasi (SLO) (Undang - Undang Republik Indonesia No. 30 Tahun 2009 Tentang Ketenagalistrikan, 2009). SLO adalah bukti pengakuan formal bahwa suatu instalasi tenaga listrik telah berfungsi sebagaimana kesesuaian persyaratan yang ditentukan dan dinyatakan siap dioperasionalkan (Peraturan Menteri Energi Dan Sumber Daya Mineral Republik Indonesia No. 38 Tahun 2018 Tentang Tata Cara Akreditasi Dan Sertifikasi Ketenagalistrikan, 2018). Pada prinsipnya, PLN akan memasang meter ekspor impor hanya setelah pelanggan PLTS atap menyampaikan sertifikat laik operasi (SLO) atas sistem PLTS atap yang terpasang. Ketentuan lebih lanjut mengenai kewajiban SLO untuk sistem pelanggan PLTS atap, berdasarkan pada kapasitas PLTS atap yang terpasang, dimana PLTS atap dengan kapasitas diatas $500 \mathrm{kVA}$ wajib memiliki SLO, sedangkan untuk kapasitas sampai dengan 500 kVA dinyatakan memenuhi ketentuan wajib SLO melalui kepemilikan hasil uji pabrikan, sertifikat produk atau dokumen standar keselamatan produk yang setara (Peraturan Menteri Energi Dan Sumber Daya Mineral Nomor 12 Tahun 2019 Tentang Kapasitas Pembangkit Tenaga Listrik Untuk Kepentingan Sendiri, 2019). Namun perlu diingat, bahwa 
bagi pelanggan PLTS dengan kapasitas di bawah 500 kVA, tetap diharuskan memiliki SLO tegangan rendah (TR), yaitu SLO atas instalasi jaringan listrik di dalam rumah atau bangunannya.

\section{Tinjauan}

Pengembangan listrik tenaga surya di Indonesia, masih mengalami berbagai tantangan. Kebijakan yang ada kini dinilai masih menyulitkan peminat dan investor listrik tenaga surya. Adapun beberapa rintangan bagi PLTS yang terkoneksi jaringan, antara lain ketentuan built operate own and transfer (BOOT) yang mengharuskan kepemilikan proyek dialihkan kepada PLN, setelah masa kontrak selesai. Pengembang listrik tenaga surya juga terpaksa menerima harga patokan berdasarkan harga listrik beban dasar (base load) batubara yang selama ini sudah dapat subsidi negara. Regulasi mengenai Biaya Pokok Pembangkitan (BPP) yang memaksakan energi terbarukan termasuk solar PV bersaing dengan PLTU batubara bisa merusak kepercayaan pasar listrik tenaga surya di Indonesia. Keputusan pemerintah pakai BPP sebagai acuan masih dipertanyakan karena dinilai tak transparan baik dalam penyusunan maupun penetapan persentase BPP. Tak ada pertimbangan dan kejelasan juga soal bagaimana perubahan atau fluktuasi BPP dari tahun ke tahun. Kondisi ini, menyulitkan pengembang dalam menghitung finansial jangka panjang. Pengembangan PLTS untuk kawasan terpencil juga membuat badan usaha berpikir ulang ketika syarat minimal elektrifikasi daerah setempat yang menjadi wilayah ijin pengusahaan sebesar 95\% sehingga memberatkan secara investasi. Pemerintah melalui berbagai Lembaga/Kementerian mempunyai kewajiban yang sama dalam hal meningkatkan kesejahteraan bagi daerah terpencil melalui berbagai macam program sehingga resiko terjadi tumpang tindih pada saat perencanaan dan pelaksanaan pembangunan wilayah menjadi besar.

Niat pemerintah mengakomodir permintaan publik agar bisa memasang PLTS surya atap di rumah, namun kebijakan jauh dari harapan regulasi adil dan transparan. Konsumen sekaligus sebagai produsen hanya bisa menjual listrik kepada PLN, namun tidak berlaku sebaliknya apabila terjadi surplus produksi listrik. Aturan harga beli PLN hanya 65\% dari listrik konsumen yang memasang solar atap, memagari konsumen hanya menghemat listrik dan membatasi konsumen jadi produsen atau penghasil listrik. Dari sisi keselamatan ketenagalistrikan tidak adanya kepastian harga SLO pembangkit perlu mendapat perhatian serius dari pemerintah.

\section{Kesimpulan}

Pemerintah terus berupaya dalam mengembangkan pembangkit listrik energi baru terbarukan termasuk PLTS dengan meluncurkan beberapa kebijakan dan regulasi seperti tersebut diatas. Beberapa kendala yang dihadapi, terutama permasalahan tidak adanya data pasti kapasitas tenaga surya terpasang karena tak ada publikasi data rutin tentang berapa kapasitas solar PV terpasang secara nasional yang terus diperbarui. Adanya kebijakan dan atau regulasi yang baru terkait pengembangan pembangkit listrik energi baru terbarukan sangat diperlukan untuk memberikan iklim investasi yang lebih bersahabat bagi calon investor. Hal ini agar pengembangan PLTS di Indonesia berjalan sesuai target dan mampu bersaing dengan pembangkit yang masih menggunakan sumber energi primer fosil sebagai bahan bakar. Dari sisi regulasi insentif, perlu adanya peraturan khusus mengenai fasilitas insentif fiskal impor barang bagi pengembangan energi baru terbarukan supaya adanya kepastian hukum, juga jelasnya prosedur pengajuan termasuk pembebanan bea masuk bahan industri PLTS. 


\section{Daftar Pustaka}

Artiningrum, T. (2014). Aspek Lingkungan Pembangkit Listrik Tenaga Bayu. Seminar Nasional Unwim, 367-382.

Dewan Energi Nasional. (2020). Bauran Energi Nasional 2020.

Fathoni, A. M., Utama, N. A., \& Kristianto, M. A. (2014). A Technical and Economic Potential of Solar Energy Application with Feed-in Tariff Policy in Indonesia. Procedia Environmental Sciences, 20, 89-96. https://doi.org/10.1016/J.PROENV.2014.03.013

Kementerian Energi dan Sumber Daya Mineral. (2020). Panduan Perencanaan dan Pemanfaatan PLTS atap di Indonesia.

Kementerian Energi dan Sumber Daya Mineral Republik Indonesia. (2020). Siaran PERS NOMOR: 122.Pers/04/SJI/2020 Tanggal 14 Maret 2020 Tentang Menengok Ladang Panel Surya Terbesar di Indonesia. https://ebtke.esdm.go.id/post/2020/03/13/2508/menengok.ladang.panel.surya. terbesar.di.indonesia

Keputusan Menteri Energi dan Sumber Daya Mineral Republik Indonesia Nomor 1567K/21/MEM/2018 Tentang Pengesahan Rencana Usaha Penyediaan Tenaga Listrik PT PLN (Persero) Tahun 2018 s.d. 2027, (2018).

Peraturan Menteri Energi dan Sumber Daya Mineral Republik Indonesia No. 38 Tahun 2016 Tentang Percepatan Elektrifikasi di Perdesaan Belum Berkembang, Terpencil, Perbatasan, dan Pulau Kecil Berpenduduk Melalui Pelaksanaan Usaha Penyediaan Tenaga Listrik, (2016).

Peraturan Menteri Energi dan Sumber Daya Mineral Republik Indonesia No. 50 Tahun 2017 Tentang Pemanfaatan Sumber Energi Terbarukan untuk Penyediaan Tenaga Listrik, (2017).

Peraturan Menteri Energi dan Sumber Daya Mineral Republik Indonesia No. 38 Tahun 2018 Tentang Tata Cara Akreditasi dan Sertifikasi Ketenagalistrikan, (2018).

Peraturan Menteri Energi dan Sumber Daya Mineral Republik Indonesia No. 49 Tahun 2018 Tentang Penggunaan Sistem Pembangkit LIstrik Tenaga Surya Atap oleh Konsumen PT. PLN (Persero), 18 (2018).

Peraturan Menteri Energi dan Sumber Daya Mineral Nomor 12 Tahun 2019 tentang Kapasitas Pembangkit Tenaga Listrik untuk Kepentingan Sendiri, (2019).

Peraturan Pemerintah Republik Indonesia Nomor 79 Tahun 2014 tentang Kebijakan Energi Nasional, (2014).

Peraturan Presiden No. 22 Tahun 2017 tentang Rencana Umum Energi Nasional, (2017).

Undang - Undang Republik Indonesia No. 30 Tahun 2007 Tentang Energi, (2007).

Undang - Undang Republik Indonesia No. 30 Tahun 2009 Tentang Ketenagalistrikan, (2009).

Undang - Undang Republik Indonesia No. 16 Tahun 2016 Tentang Pengesahan Paris Agreement To The United Nations Framework Convention on Climate Change (Persetujuan Paris Atas Konvensi Kerangka Kerja Perserikatan Bangsa-Bangsa Mengenai Perubahan Iklim), (2016).

Tenriabeng, B., Rifai, B., \& Sumardi, J. (2013). Peranan PT. PLN (Persero) dalam Pelayanan Kelistrikan. Program Pascasarjana UNHAS, 1-12.

Vernon, P. (2015). Sustainable development goals. Economist (United Kingdom), 411(8953).

Wu, P., Ma, X., Ji, J., \& Ma, Y. (2017). Review on Life Cycle Assessment of Greenhouse Gas Emission Profit of Solar Photovoltaic Systems. Energy Procedia, 105, 1289-1294. https://doi.org/10.1016/j.egypro.2017.03.460 